\title{
Development of an analytical function for optimizing the capacity of spring water storage structure
}

\author{
A. K. Vashisht ${ }^{1}$
}

Received: 14 August 2015/Accepted: 9 September 2016/Published online: 23 September 2016

(c) Springer International Publishing Switzerland 2016

\begin{abstract}
Now, there is no doubt that the Greater Himalayan region is facing the impact of climate change and that is specifically visible through the noticeable changes in the discharging patterns of the springs from the last four to five decades. Either the springs have become seasonal or their discharge rates (particularly during recession periods) have diminished to significant extent. In this changing scenario, the long-term survival of the inhabitants in the region vests in the adaption of suitable water management practices; and the most feasible option is to reserve the water stock when it is in excess during monsoon/post-monsoon season. However, the construction/purchase of water storage structure may become highly uneconomical for below mid-class families if the selected capacity of the structure is more than optimal. On the contrary, the undersized (than optimal capacity) will fail to serve its purpose. Thus, for accurately optimizing the capacity of water storage structure, an analytical function has been proposed in the present study. The application of the proposed function has been demonstrated by considering the realistic number of dependents on a western-Himalayan gravity spring named 'Fakua'. The analyses show that with increase in the water shortage period, per cent reduction in the optimized storage from the actual demand decreases and this particular behavior depends on the spring discharge rate during recession period. With the use of formulated analytical function, the available discharge from the spring during recession period can be managed much more efficiently and economically in comparison to other flow mass curve methods.
\end{abstract}

A. K. Vashisht

akvashisht74@yahoo.com

1 College of Agricultural Engineering and Post-Harvest Technology, Ranipool 737135, Sikkim, India
Keywords Spring hydrology $\cdot$ Recession period · Optimal capacity of water storage structure - Western Himalayan region $\cdot$ Spring water management

\section{Introduction}

The Greater Himalayan region which covers approximately 7 million $\mathrm{km}^{2}$ of area is known as the Water Tower of Asia (Qiu 2008; Xu 2008). The Himalayas form a barrier to atmospheric circulation for the summer and winter Westerlies and due to its highly heterogeneous geography, the region has great climatic variability (Xu et al. 2009). It can be better judged from the region's average annual precipitation that ranges from less than $50 \mathrm{~mm}$ in the Taklimakan Desert in the Northwest to about $11,117 \mathrm{~mm}$ in the Eastern Himalayas (Hofer and Messerli 2006). Regional-level studies in the Greater Himalayas have also confirmed this (Beniston 2003; IPCC 2007) and specifically pointed out that the region is experiencing increasing and decreasing precipitation trends (Ma et al. 2009; Mukherjee et al. 2014; Shrestha et al. 2000; Xu et al. 2009) from the last four to five decades. It is a well-known fact that the precipitation occurring over a larger time period with lesser intensity would be more effectively utilized rather than when it occurs within a short time span with greater intensity (Mall et al. 2006). Various studies have predicted that rainfall along with its intensity will increase in the coming decades (Rees and Collins 2006; Singh et al. 2008; Tambe et al. 2011). The increase in intensity of the rainfall increases the runoff component in comparison to the recharging of the spring catchments. As a result, the discharge rate of the ecologically important springs can be impacted severely by this change in climate (Levison et al. 2014). Since springs are the major source of water for 
drinking and household consumption (Tiwari and Joshi 2012; Vashisht and Sharma 2007), the mankind's survival in the region solely depends on the adaption of certain sustainable water management practices. The feasible adaption technique to the present water scarcity problem in recession period is to store when it is in excess during monsoon/post-monsoon season. The selection of storage capacity depends on the discharging pattern of the spring in recession period and on the number of users. Therefore, its construction/purchase may become highly uneconomical if selected capacity of the structure is more than optimal. Conversely, the undersized capacity (than optimal) will fail to serve the purpose. The accurate prediction of spring's discharge rate can assist in evaluating the difference in demand and availability of water during recession period, and on that basis, the storage capacity can be optimized. Based on the above discussion, the specific objectives of the present study are:

1. To predict the spring discharge rate for recession period after formulating its characteristic discharge function.

2. To formulate an analytical function for optimizing the capacity of the storage structure for assuring roundthe-year uninterrupted water supply.

\section{Description of spring catchment and data collection}

The Greater Himalayas can be divided into six primary litho-tectonic zones which occur in parallel belts. These zones are named as Sub (or Outer) Himalaya; the Lower (or Lesser) Himalaya; the Great (or Higher) Himalaya; the Tibetan (or Tethys) Himalaya; the Indus-Tsangpo suture; and the Trans-Himalaya (Gansser 1964). However, in the Western Himalayas, the Indus-Tsangpo suture and the Trans-Himalayan zones are grouped under one tectonic zone called the Trans-Himalaya. The Lesser Himalayan zone bounded the main central thrust (MCT) in the north and main boundary thrust (MBT) to the south and is primarily composed of sedimentary rocks from the Indian platform. Rock sequences are highly disturbed in this zone and are characterized by stacking of sedimentary and crystalline nappes. The spring under study is in Garhwal region of this zone. The Garhwal (in the Western Himalayan region) is drained almost entirely by Ganga and its tributaries. This region belongs to the Krol formation and is having phyllite lithology. The spring named Fakua is located near village Ranichauri at geographical location of $30^{\circ} 18^{\prime} 44.13^{\prime \prime} \mathrm{N}$ latitude and $078^{\circ} 24^{\prime} 14.25^{\prime \prime} \mathrm{E}$ longitude and at an elevation of $1795 \mathrm{~m}$ above mean sea level, in TehriGarhwal district of Uttarakhand, India (Fig. 1a). It is a gravity spring and is having Western aspect. The springcatchment's soils are formed under cool and moist climate from rocks of biotite schist and phyllitic material. These brown to grayish-brown and dark gray soils are shallow and gravelly, and are impregnated with weathered fragments of stones and parent rock (Fig. 1c). In general, these are non-calcareous and neutral to slightly acidic in reaction. The Oak plants and minor shrubs like Myrsine Africana, Berberis lyceum, Rubus ellipticus and Sarcococca hookeriana are dominating the area (Fig. 1b).

The spring's discharge rate and the region's rainfall were recorded daily for 8 years from 1999 to 2006 under the project named All India Coordinated Research Project (AICRP) on Groundwater Utilization (GWU). The $70-80 \%$ of the total rainfall (i.e., $1200-1400 \mathrm{~mm}$ annually) received by the spring catchment occurs in the monsoon season and rest due to winter Westerlies.

\section{Analytical development}

The representation of spring's discharge characteristics in mathematical terms is known as spring discharge function and its formulation includes the following steps.

1. Development of spring hydrographs and demarcation of recession curves,

2. Fitting of recession curves with most representative mathematical components,

3. Formulation of spring discharge function.

Figures 2, 3, 4, 5, 6 , 7, 8, 9 show the demarcated recession curves for all the 8-year data of Fakua spring. In hydrological studies, the precision of the developed models/functions depends on the precise fitting of recession curves with one or more number of mathematical components. It is a worldwide accepted procedure to understand the internal information of the aquifer (Chang et al. 2015). In general, it is believed that the fitting of recession curves with two components (may be non-exponential, exponential, or combination of these) is appropriate for evaluating accurate results (Boussinesq 1904; Mangin 1975; Amit et al. 2002; Bam 2011). Recently, Diodata et al. (2014) have developed model for spring discharge estimation by considering that groundwater is represented by single reservoir which can be conveniently described by singlevalued function. However, the mentioned generalizations cannot be considered perfect for all the springs, because unless the recession curve's decay is uniformly following particular slope, the number of components required to fit it varies with the number-of-time it changes its general gradient (and that is also for a considerable time period). The change in the general slope of the recession curve for a duration of very short time can be attributed to the heavy 

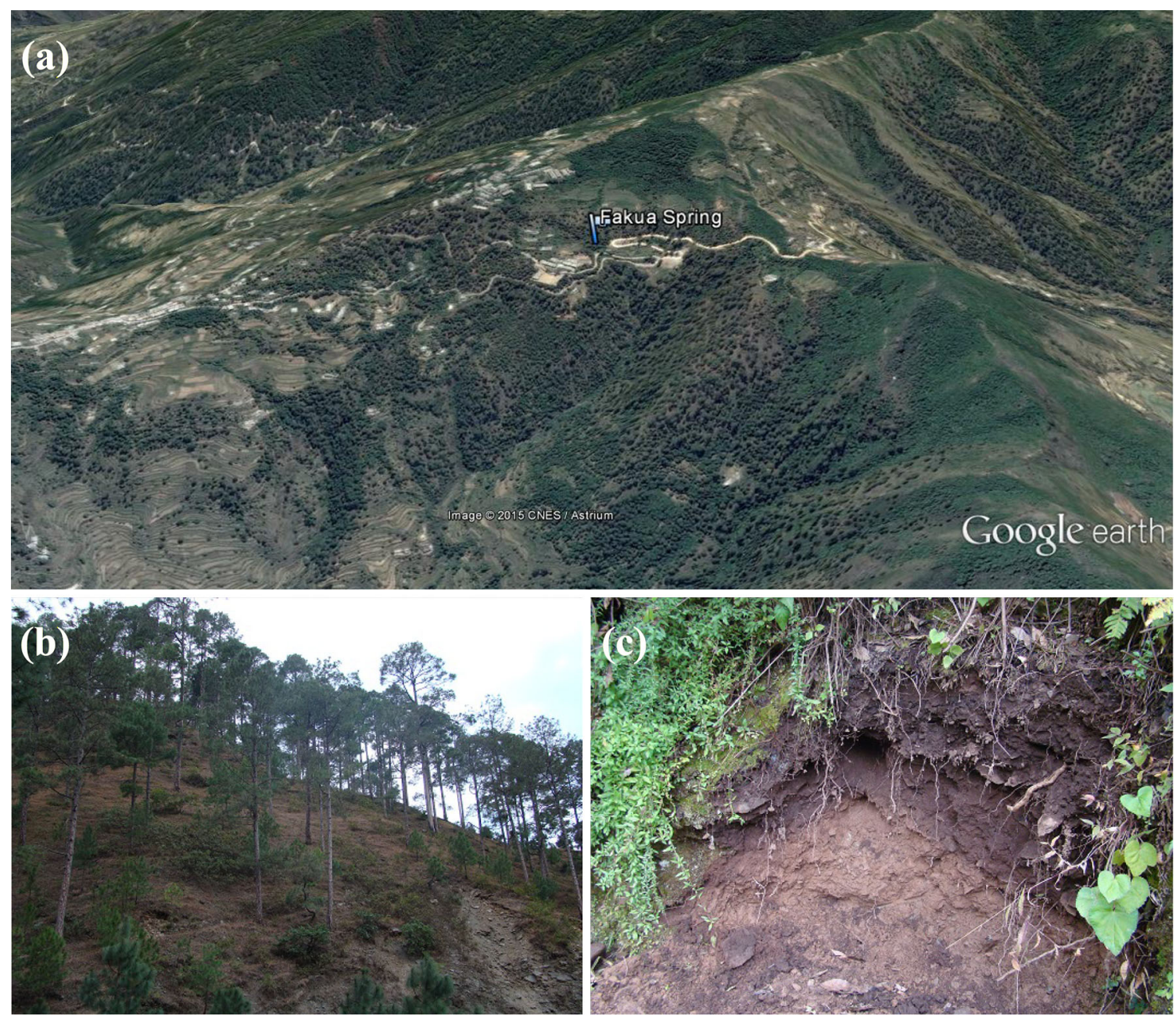

Fig. 1 a Google Earth image of Fakua spring; b vegetation in its catchment; c excavated soil in the catchment

recharging event within the normal recharging period and is a regular feature (see Fig. 3). The occurrence of these smaller duration bumps in the recession curve can be well understood by studying time-lag concept (Vashisht and Sharma 2007). Geologically, all spring catchments have their unique features that affect the springs' temporal discharge patterns. Hence, the number of mathematical components that can simulate the discharge pattern of a spring draining a homogeneous catchment with minimum error will certainly vary from the spring that is discharging the catchment storage having varied geohydrology. The catchment storage of a spring may comprise formations of different porosities and discharging characteristics which are reflected by the change in general slope of the recession curve. The individual formations may or may not be located in a complex geometrical pattern within the catchment (Fig. 10). It may be possible that one or more formations are in direct link with the spring outlet, whereas others may not. From hypothetical sketch (Fig. 10), it is apparent that the formations 1,4 , and 5 are in direct link with the spring outlet, whereas the formations 2 and 3 are indirectly linked through other formations. Depending on the difference in heads of water in adjoining formations, water movement from one to other formation(s) occurs. Obviously, the directly linked formation with higher permeability will drain off earlier and will provide steepness to the slope of recession curve. On the other hand, the drainage rate of indirectly linked formations will depend on the formation having lowest permeability, and consequently, the slope of the recession curve will be gentle. Therefore, negating the precedent hypothesis (i.e., fitting the recession curves with two mathematical components only), it is essential to find out first the number of components that can fit the recession curves with maximum accuracy. It is worth to mention here that the decision regarding the number of mathematical components required to fit the recession curve is generally taken by the visual examination of the recession curves in which our concern is to demarcate the predominant general slopes. In the present study, all the curves are showing three major 


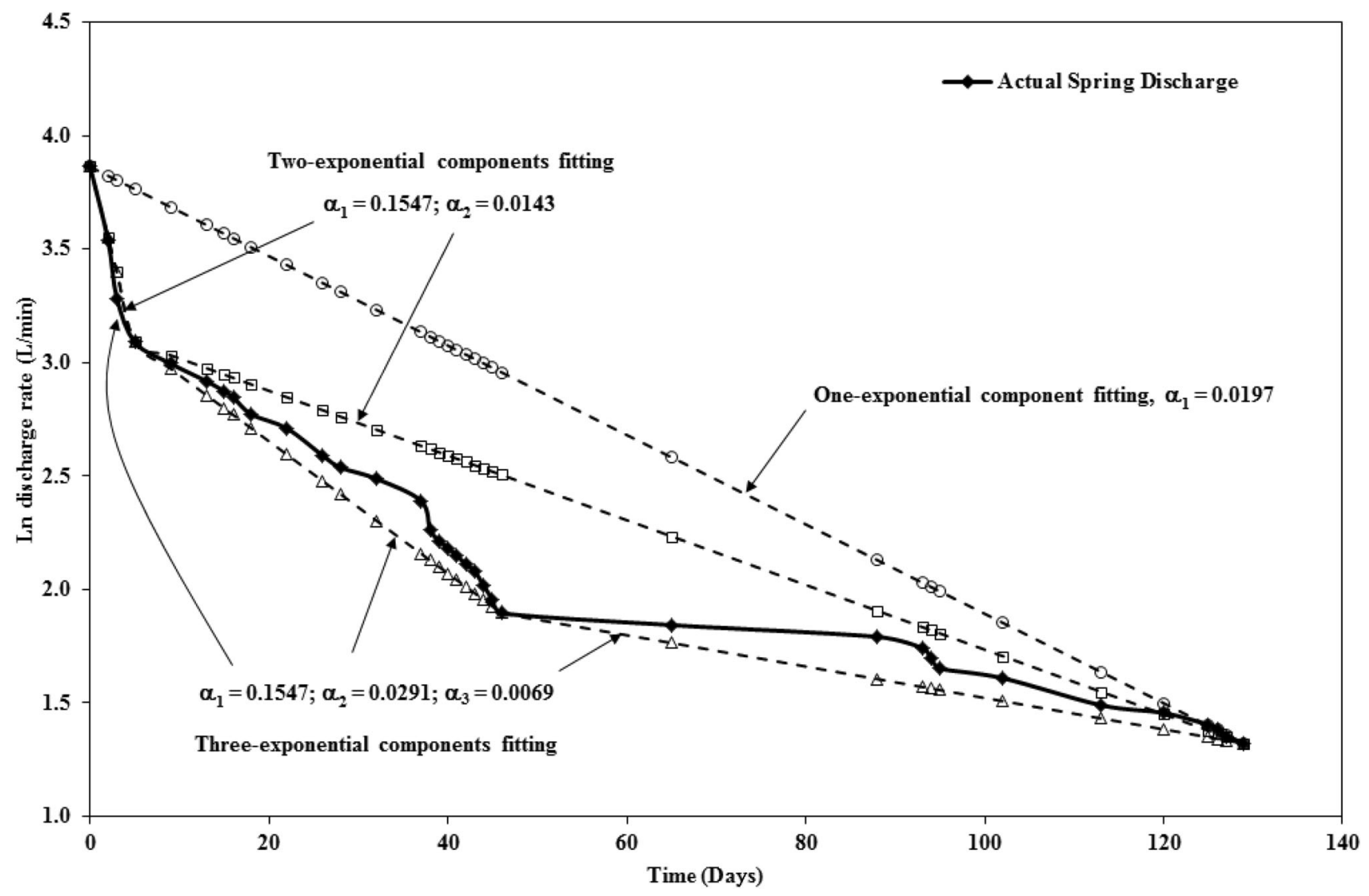

Fig. 2 Recession curve for the year 1999 fitted in one-, two-, and three-exponential components for comparison

slopes, and therefore, it is proposed to check the accuracy as well as comparison of the fitting of recession curves with one-, two-, and three-exponential components. For the purpose, the years 1999, 2003, and 2004 were selected specifically as the slopes of the recession curves for the mentioned years are comparatively inconsistent with the general trend of recession curves in the rest of the years. A general form of the mathematical function that can be used to evaluate the spring yield after fitting the recession curve with $N$ exponential components (Amit et al. 2002) can be written as:

$$
\begin{aligned}
V=\left.\left\{\sum_{t_{i}=T_{i-1}}^{T_{i}-1} Q_{0 i} \times \exp \left[-\alpha_{i} \cdot\left(t_{i}-T_{i-1}\right)\right]\right\}\right|_{\text {for } i=1 \text { to } N-1} \\
+\left.\left\{\sum_{t_{N}=T_{N-1}}^{T_{N}} Q_{0 N} \times \exp \left[-\alpha_{N} \cdot\left(t_{N}-T_{N-1}\right)\right]\right\}\right|_{\text {for } i=N}
\end{aligned}
$$

In Eq. (1), $V$ is the spring yield for the recession period; $Q_{0 i}$ and $Q_{0 N}$ are the discharge rates of the $i$ th and $N$ th components of the recession curve at the commencement, respectively; $T_{i}$ and $T_{N}$ denote the total number of days in $i$ th and $N$ th exponential components, respectively; $\alpha_{i}$ and $\alpha_{N}$ indicate the slope of the $i$ th and $N$ th exponential components of the recession curve on the logarithmic scale, respectively. Here, it is essential to mention that peak of the hydrograph or the first value of the recession period is kept against time equal to zero. As proposed, the recession curves for the selected years 1999, 2003, and 2004 are fitted with one-, two-, and three-exponential components (Figs. 2, 6, 7). Evaluated exponential coefficients (i.e., slopes), initial discharge rates for individual components, and the durations (i.e., the number of days for which the particular exponential component fits the recession curve) for the three cases in all the 3-year recession curves are presented in Table 1. Incorporating the tabulated values in Eq. (1), the spring yields for the mentioned years are evaluated and compared with the actually recorded yield (Table 1). Perusal of Table 1 indicates that the fitting of the recession curves for the years 1999, 2003, and 2004 with three-exponential components are predicting the yield with greater accuracy. It means that the recession curves of the Fakua spring can be characterized accurately with the three-exponential components. It is evident from the results that the catchment storage of the spring comprises, majorly, three geological formations which may be interlinked or separate from each other by pervious/impervious layers. 


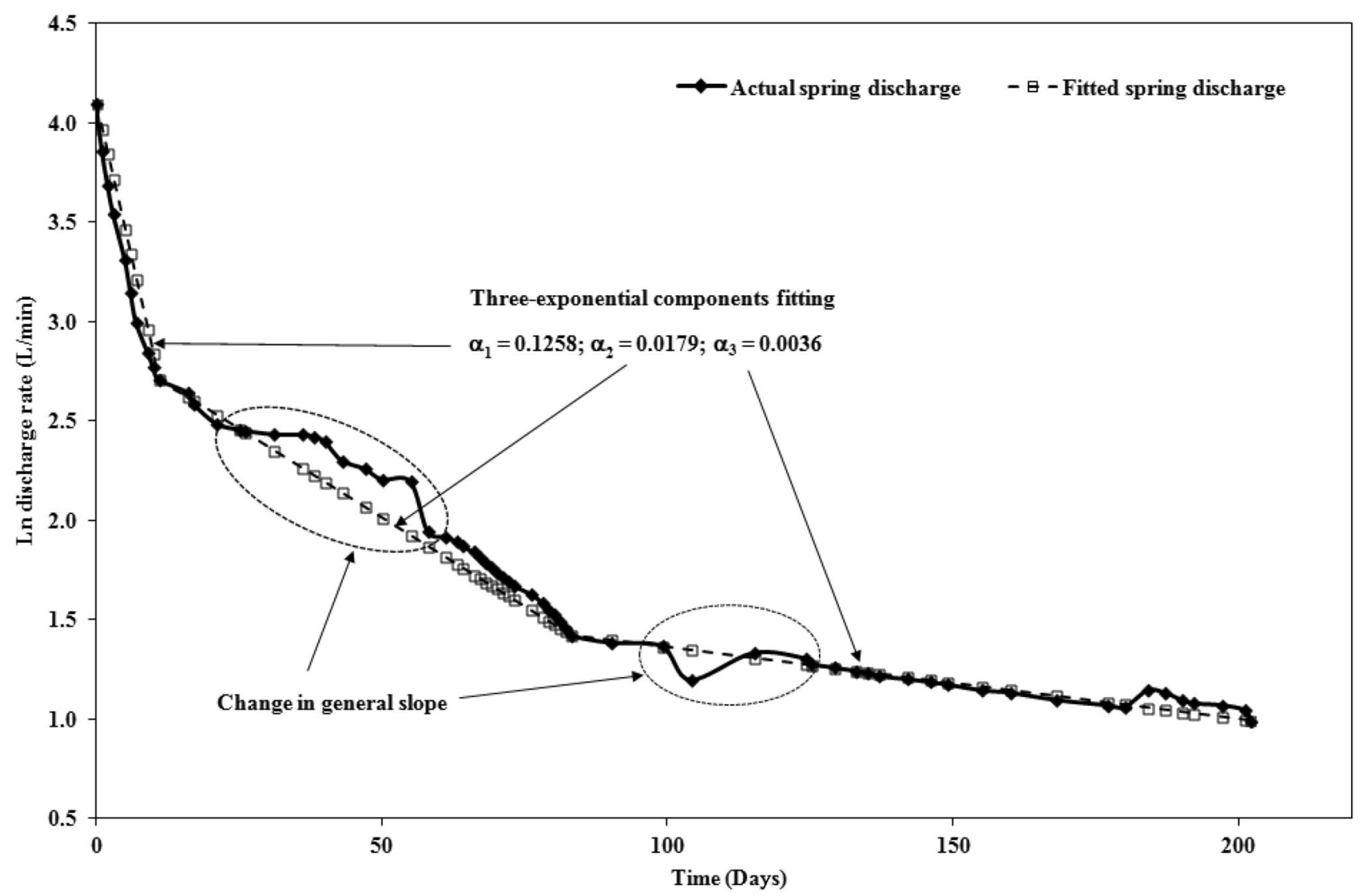

Fig. 3 Recession curve for the year 2000 fitted in three-exponential components

However, it is necessary to point out that the hydrographs' analyses cannot delineate the actual geometry, location, and dimensions of these porous formations.

The evaluated exponential coefficients (i.e., the slopes $\alpha_{1}, \alpha_{2}$, and $\alpha_{3}$ ) for the three demarcated segments in all the eight recession curves are depicted in Figs. 2, 3, 4, 5, $6,7,8,9$ and are also presented in Table 2. The formulation of spring's discharge function requires its characteristic exponential parameters. However, the year-on-year variation in different parameters (especially exponential coefficients) is the major constraint in its formulation. Evaluating the ratios of maximum to minimum values is an appropriate way of quantifying the variation in exponential coefficients. Ideally, this ratio will approach to unity for the spring having similar discharging pattern for all the recession periods. However, it is not feasible in case of any natural hydrological system. Data analyses show that errors in the computed results for most of the recession periods remain within $10 \%$ when the said ratio for first-exponential coefficients remains less than five. The variations in the second- and third-exponential coefficients do not alter the results to much extent as the initiation of second-exponential component depends on the end-value of the first and so on. Other than the mentioned reason, the firstexponential component represents the higher flow rate from the spring catchment with major contribution to this flow from the catchment's formation having highest permeability. Therefore, the inappropriate selection of first-exponential coefficient may generate huge errors in the computed spring yields. Moreover, the increase in the ratio can be attributed to the exceptional behavior of the spring caused due to dry- or wet-year and, therefore, cannot be considered as spring's general behavior for characterizing it. This analytical demarcation defines two separate procedures for evaluating the generalized characteristic values of parameters of the spring discharge function.

1. Procedure 1: In case the ratio of maximum to minimum values of first-exponential coefficients is less than five, then, taking the arithmetic mean of the values of all the parameters, individually, for the data years gives the spring characteristics. The evaluated mean values are then incorporated in Eq. (1) for formulating the spring discharge function.

2. Procedure 2: The occurrence of extremely dry- or wetyear during the data recording period causes the said 


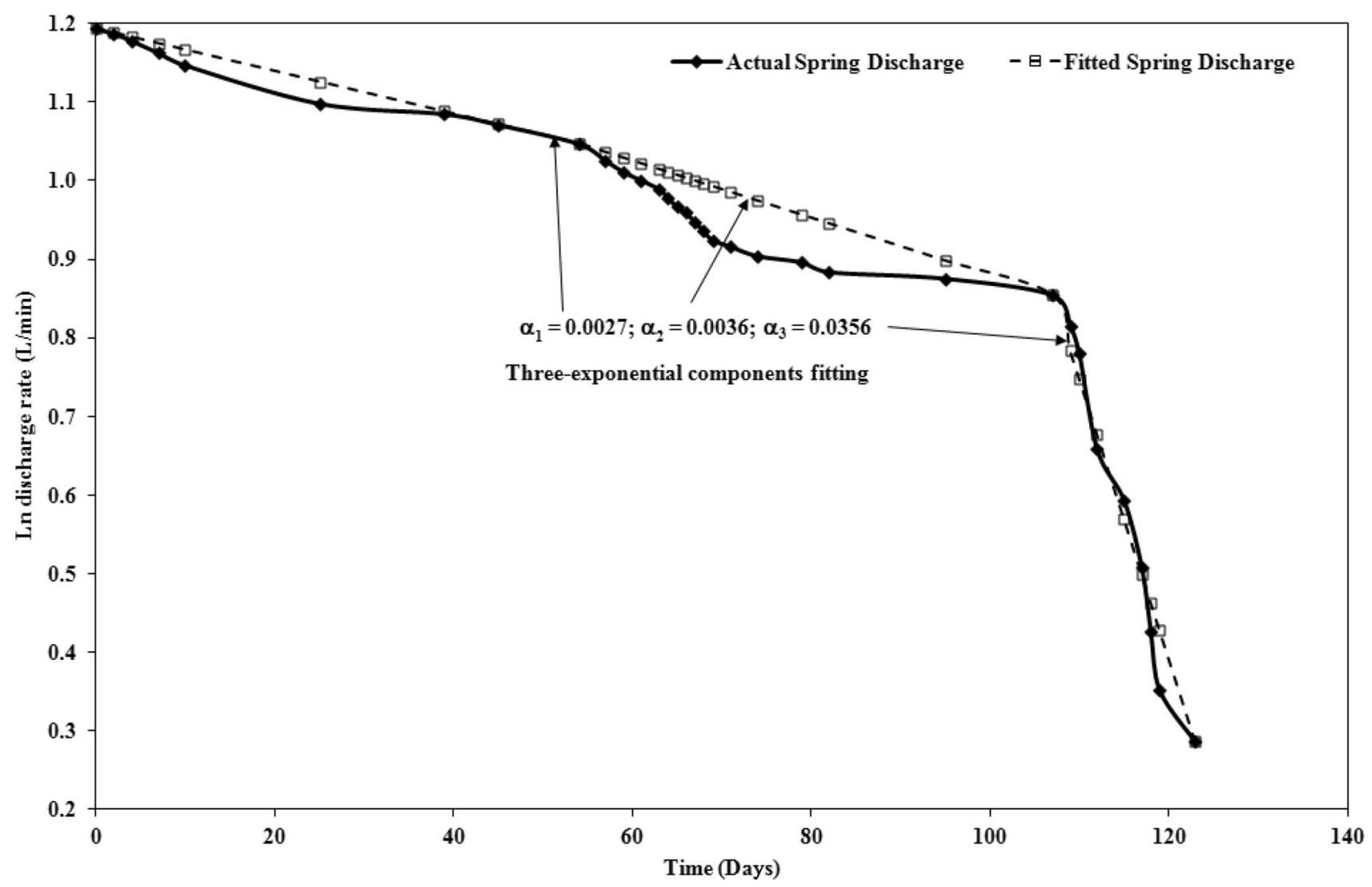

Fig. 4 Recession curve for the year 2001 fitted in three-exponential components

ratio to exceed five. In that case, the data for the year with exceptional behavior of spring are not considered in evaluating the general spring characteristics. Moreover, the weighted mean (on the basis of duration of particular component that is used for evaluating slope) of exponential components is evaluated. However, for computing the characteristic values of other parameters, arithmetic mean can be taken.

In the present study, the 8-year values of first-exponential coefficients range from a minimum of 0.0027 to a maximum of 0.1547 (with ratio of maximum/minimum $=57.29$ ). The computed ratio restricts the adoption of procedure 1 for developing spring discharge function. Moreover, it is also a fact that in the present changing climate scenario, such a high variation in the exponential coefficients is not unexpected. Following the instructions as mentioned in procedure 2, the weighted mean of all exponential components and arithmetic mean of other parameters are evaluated (by excluding the data for year 2001) and are tabulated in the last column of Table 2.

By incorporating the mean characteristic values from the last column of Table 2 in Eq. (1), the spring discharge function is formulated as:

$$
\begin{aligned}
V= & \left\{\sum_{t_{1}=T_{0}=0}^{24-1} Q_{01} \times \exp \left[-0.0699 \times\left(t_{1}-0\right)\right]\right. \\
& \left.+\sum_{t_{2}=24}^{78-1} Q_{02} \times \exp \left[-0.0186 \times\left(t_{2}-24\right)\right]\right\}\left.\right|_{\text {for } i=1 \text { to } 2} \\
& +\left.\left\{\sum_{t_{3}=78}^{T_{N}} Q_{03} \times \exp \left[-0.0087 \times\left(t_{3}-78\right)\right]\right\}\right|_{\text {for } i=3} .
\end{aligned}
$$

In Eq. (2), $Q_{01}$ is the initial discharge rate of first segment of the recession period with a mean duration of 24 days and $Q_{02}$ is the initial discharge rate of second segment of the recession period and is equal to the discharge rate of the spring in the end of first segment. It means that the last discharge rate value at $t_{1}$ of the first segment will be the initial discharge rate for the second segment. Similarly, $Q_{03}$ is the initial discharge rate of the third segment of the recession period and is equal to the discharge rate of the spring in the end of second segment. For testing the efficiency of the formulated spring discharge function, the actually monitored discharge rates $Q_{01}$ (Row 3, Table 2) are incorporated consecutively in Eq. (2), and the daily discharge rate predictions for the years 1999-2006 (except 2001) are made for the actual recession periods selected for the analyses (as 


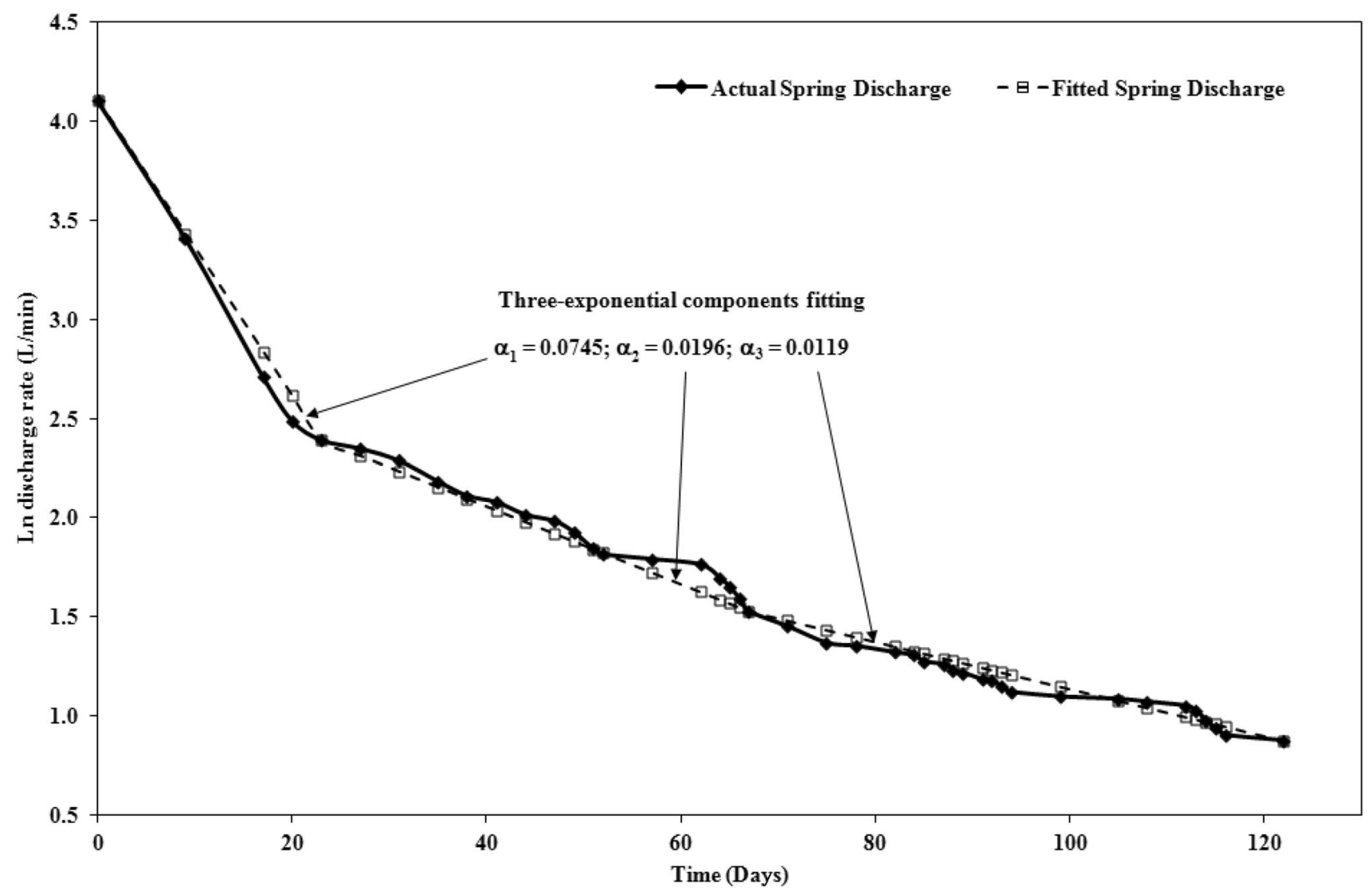

Fig. 5 Recession curve for the year 2002 fitted in three-exponential components

tabulated in Row 12 of Table 2). Though the mean duration evaluated for the third segment of the recession period equals 73 days, for the purpose of verifying the formulated discharge function's performance, the actually recorded durations are considered for the third segment of the recession period. It is because of the reason that the varied durations of recession periods were witnessed during the data collection years. But, for the first- and second-exponential components, the evaluated mean durations (Rows 5 and 8, last column, Table 2) are used. The over- and under-prediction errors from the actual spring yield are presented in Table 3 .

The predicted results are comparable with the actual observations except for the years 1999 and 2006. It may be due to low rainfall in both the years (i.e., 939.70 and $897.00 \mathrm{~mm}$ ) as the average annual rainfall of the region is $1110.03 \mathrm{~mm}$. From the results and the above discussion, it is evident that the spring discharge function (2) can be used for predicting the discharge rate of the spring with near accuracy.

\section{Formulation of analytical function for optimizing the capacity of water storage structure}

It has been noticed that the families which are solely dependent on a spring water supply are least concerned about the capacity of storage structure. Generally, they are more concerned about its location, its aesthetic looks, and their capacity to spend money on it (Khastagir and Jayasuriya 2010). In actual practices, a number of other aspects that directly influence the selection of storage structure's capacity are generally overlooked. These aspects include: actual daily water requirement (including all types of uses); availability of spring water during the recession period; and the distance of storage structure from spring, as a considerable quantity of water is generally wasted during its conveyance (specifically through plastic pipes). In addition, the capacity selection of the storage structure becomes more important when this structure has to include the reserve capacity for assured water availability in the upcoming recession period. For this particular reason, the approach 'one size fits all' becomes flawed here as it is only practicable when the water availability is more than its actual consumption. Besides, Khastagir and Jayasuriya (2010) have also pointed out that this approach is flawed even for rainwater tank selection when one considers the rainfall characteristics within a region where mean annual rainfall varies significantly with location. Their justification was based on the variability of source (i.e., rainfall); whereas in the present study, source (i.e., spring) is the 


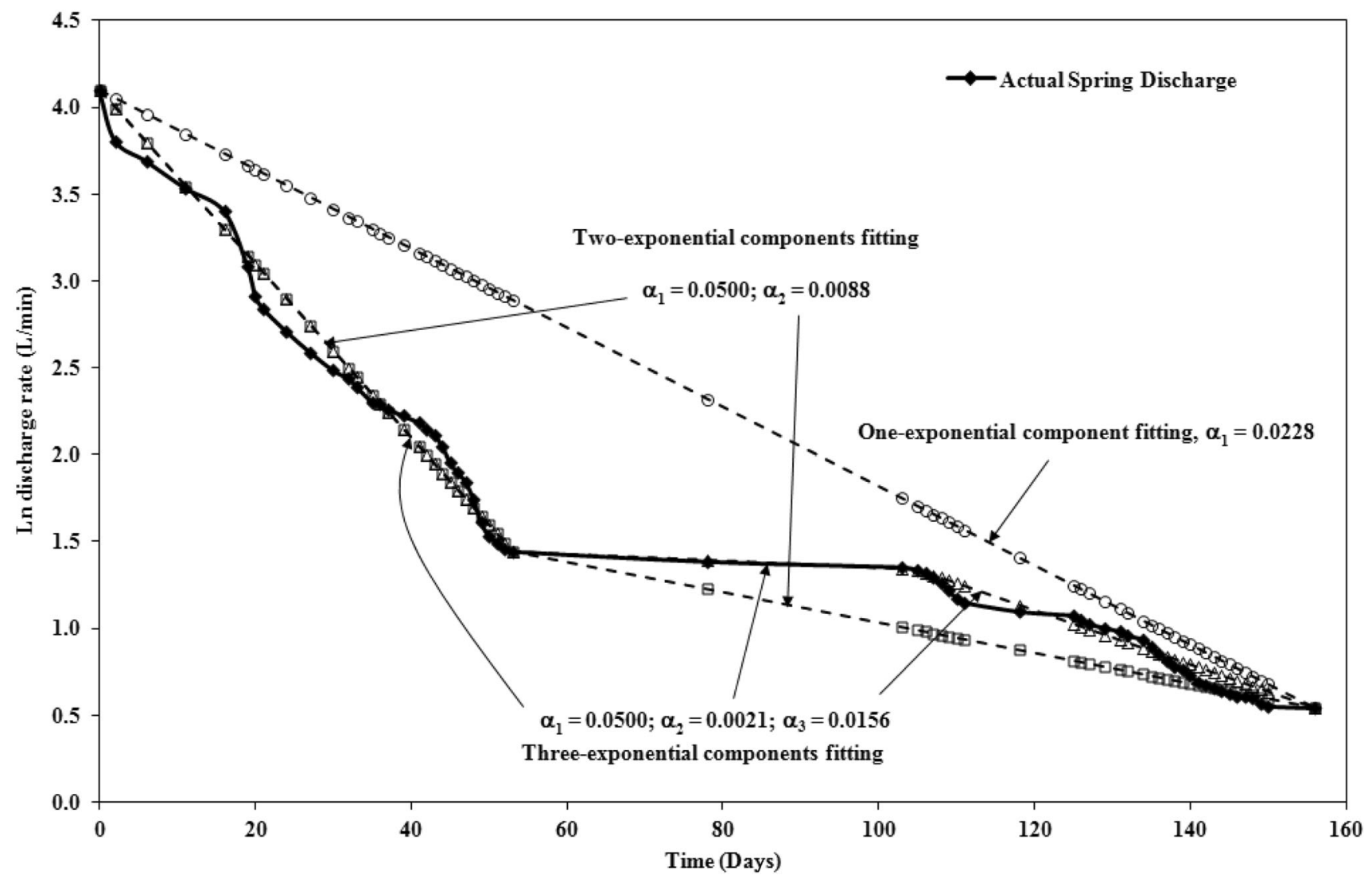

Fig. 6 Recession curve for the year 2003 fitted in one-, two-, and three-exponential components for comparison

same and any variation in its discharge rate affects the need of all its dependents in equal proportion. Considering that residents restrict the use of available water for domestic purposes only (which is fortunately true in recession period); then the size of a family is the prime criterion for selecting the capacity of storage structure. Obviously, the capacity of the storage structure will vary with the family size. The storage required for other essential and unforeseen uses during recession period can be included while optimizing the capacity of storage structure.

Say, a village which is completely dependent on a spring has a population of $P_{N}$ persons. Consider that $D$ Liters per capita per day (Lpcd) is their daily domestic water demand. This demand includes drinking, cooking, laundry, and toilet flushing needs only. As water demand is directly related to the number of persons, the total daily water demand $T_{D}$ of $P_{N}$ persons can be easily calculated as:

$T_{D}=P_{N} \times D$.

It means that a water supply of $T_{D} \mathrm{~L} /$ day is the basic requirement (i.e., minimum) of $P_{N}$ persons and that should be available throughout the year irrespective of the spring discharge rate. If $T_{D}$ is less than the daily discharge rate of the spring during the recession period, then there is no need to optimize the capacity of water storage structure and 'one size fits all' approach will be applicable. Conversely, as soon as daily spring discharge rate becomes less than the $T_{D}$, water shortage period (say $\left.T_{\text {short }}\right)$ starts, for which a storage structure of optimum capacity is required. During recession period, the spring discharge rate declines with time, and therefore, its difference from $T_{D}$ increases continuously and reaches to a maximum value at the end of $T_{\text {short }}$. Further, the end of recession period is a transition point, as after that, accession period starts. Most importantly, from the eight-year discharge rate pattern of the spring, it is observed that the slope of the accession curve remains very steep in general. The instant increase in discharge rate of the spring enables it to pass on the $T_{D}$ within two to three days and is not considered in the analyses. Hence, the present study's concern is only up to the end of recession period and the focus is on the accumulation of daily differences between actual demand and availability of spring water for the $T_{\text {short }}$. Based on Eq. (2) and the above mentioned discussion, the analytical function for evaluating optimized storage capacity of structure considering no wastage and excess use $\left(O_{\text {sc-w }}\right)$ can be written as: 


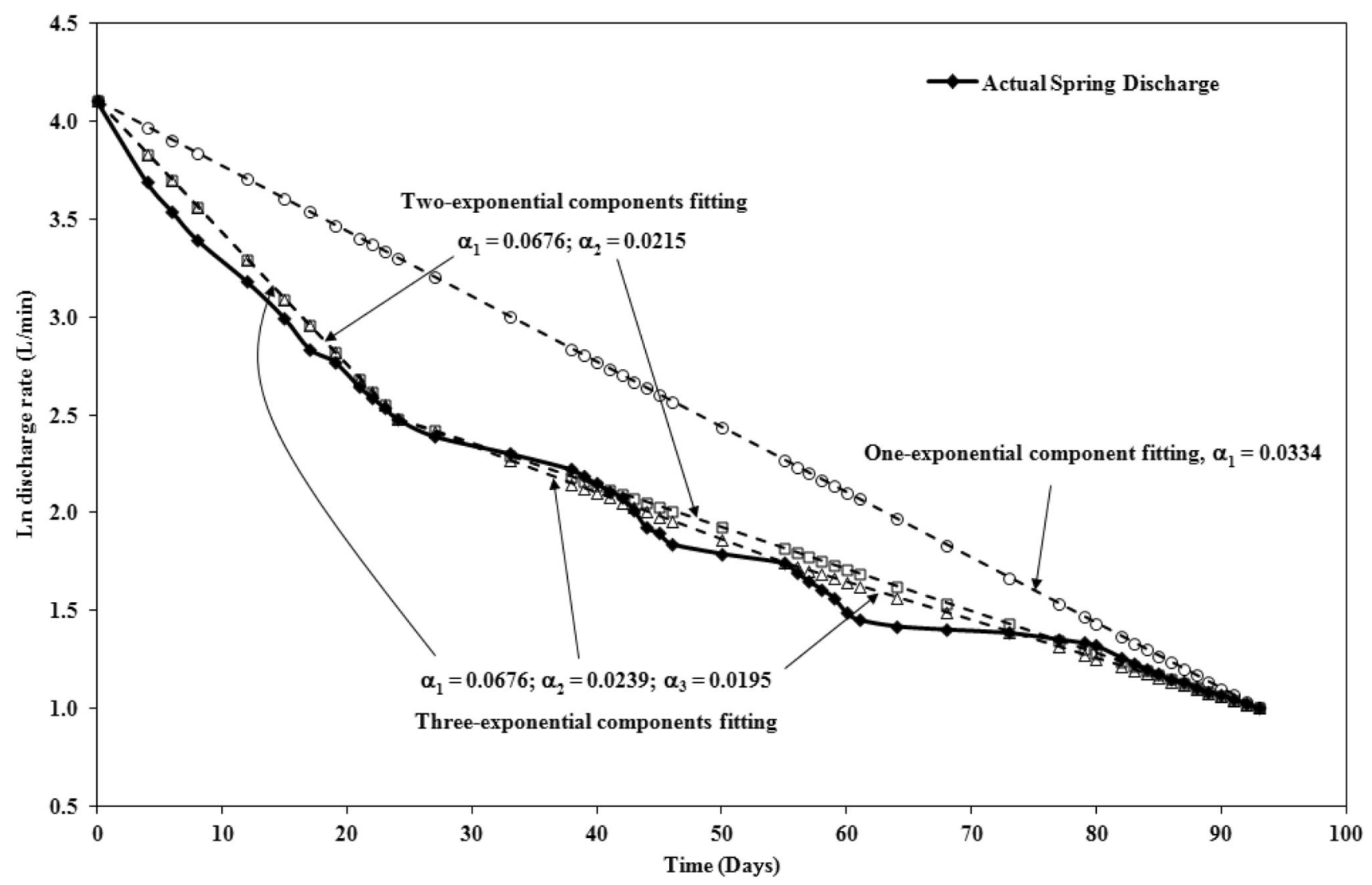

Fig. 7 Recession curve for the year 2004 fitted in one-, two-, and three-exponential components for comparison

$$
\begin{aligned}
O_{\text {sc }-\mathrm{w}}= & P_{N} \times D \times T_{\text {short }} \\
& -\left\{\begin{array}{c}
\left.\sum_{t_{1}=T_{0}=0}^{24-1} Q_{01} \times \exp \left[-0.0699 \times\left(t_{1}-0\right)\right]+\right\} \\
\left.\sum_{\text {for } i=1 \text { to } 2}^{78-1} Q_{02} \times \exp \left[-0.0186 \times\left(t_{2}-24\right)\right]\right\}
\end{array}\right. \\
& -\underbrace{\left\{\sum_{t_{2}=24}^{T_{t_{3}}=78} Q_{03} \times \exp \left[-0.0087 \times\left(t_{3}-78\right)\right]\right\}}_{\text {for } i=3} .
\end{aligned}
$$

In Eq. (4), the letters 'sc' in subscript of symbol $O_{\text {sc-w }}$ represent 'storage capacity' and letter ' $w$ ' as the wastage and excess use of water. Depending on the location of water storage structure, its distance from the tapping of water source (i.e., spring) may range from few meters to several kilometers, and in general, the water is conveyed through plastic pipes. As per the author's experience, regular maintenance of this conveyance system is the prime requirement for uninterrupted and leakage-free water supply, failing of which leads to the substantial outflow of water (i.e., wastage) from the pipe joints and cracks (caused due to adverse weather conditions and placing of pipe at uneven slopes). Furthermore, there is always an unforeseen demand of water like washing of vehicles, house cleaning on eve of any festival, and visits of guests etc. For considering this increased use and wastage, the total daily water demand is increased by $W \%$. Therefore, the analytical function for evaluating optimized storage capacity $O_{\mathrm{sc}}$ (considering wastage and excess use) of structure can be written as:

$O_{\mathrm{sc}}=O_{\mathrm{sc}-\mathrm{w}} \times\left(1+\frac{W}{100}\right)$.

\section{Application of the formulated function}

The data analyses of the Fakua spring show that the mean peak discharge rate of the spring at the start of the recession period is equal to $62.54 \mathrm{~L} / \mathrm{min}$ (Table 2). In the data monitoring years, a recession period of maximum duration of 213 days was recorded which is 63 days more than the average duration of 151 days. For optimizing the capacity of water storage structure, this extreme duration of recession period is considered. Purpose is to make the storage 


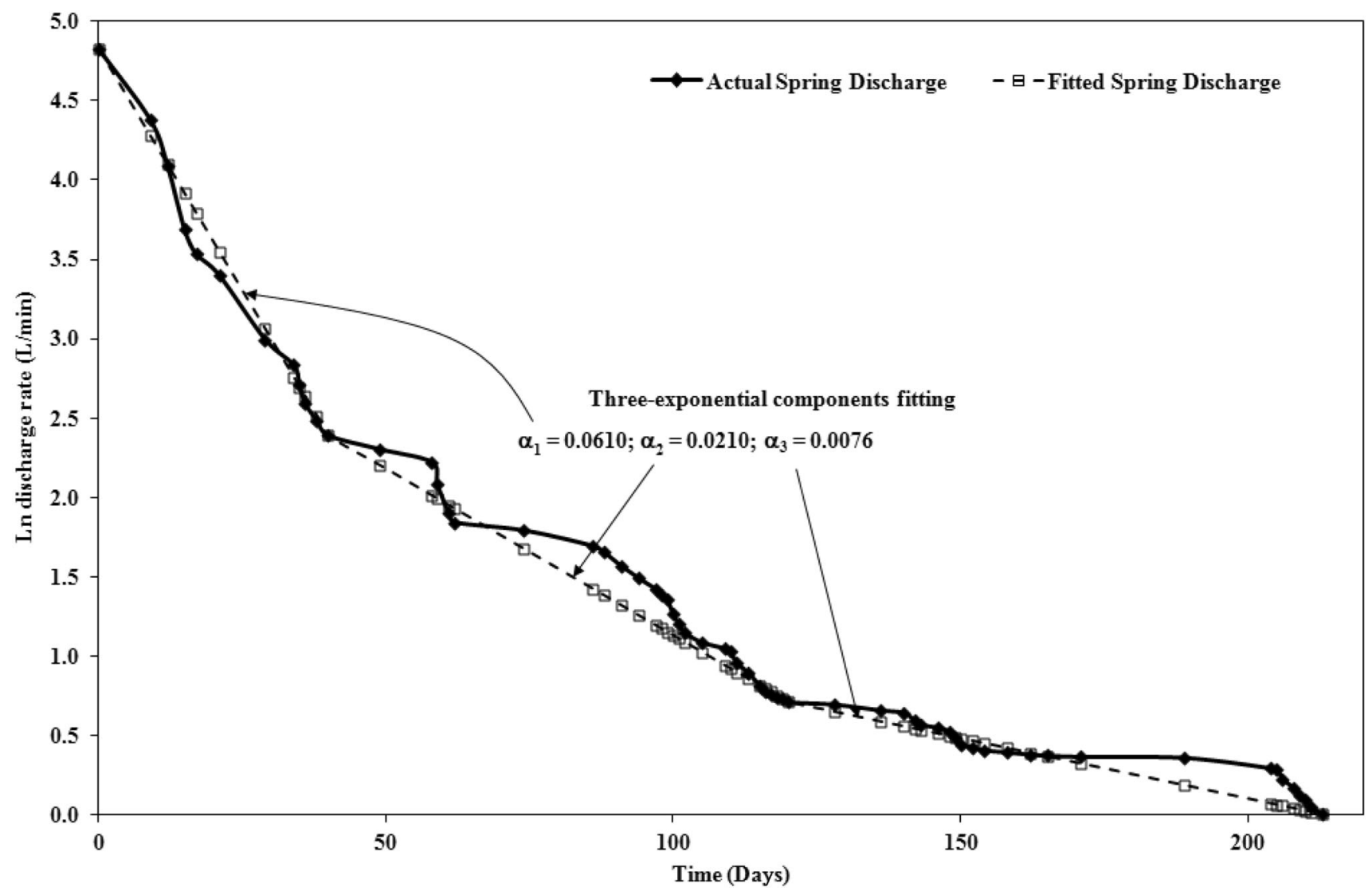

Fig. 8 Recession curve for the year 2005 fitted in three-exponential components

structure more reliable under extreme recession conditions. The incorporation of $Q_{01}=62.54 \mathrm{~L} / \mathrm{min}$ and $T_{N}=213$ days in Eq. (2) leads to the recession curve as shown in Fig. 11. Consider that the village has a population of 160 which is completely dependent on the Fakua spring for their daily domestic needs. Ministry of Drinking Water and Sanitation, Government of India (GOI) (MoDW\&S 2011) in its proposed 12th 5-year plan (i.e. 2012-2017) has stressed to achieve the target of supplying the rural domestic water demand $D$ at rate equal to $70 \mathrm{Lpcd}$. The same standard is fixed for rest of the calculations. Therefore, the total volume of water required for 160 persons daily (excluding the wastage and excess use) can be calculated from Eq. (3) as:

$T_{D}=160 \times 70=11,200 \mathrm{~L} /$ day.

Rewriting calculation (6) in smaller units (i.e., the units in which the discharge rate is usually monitored), it converts to:

$=11,200 /(60 \times 24)=7.78 \mathrm{~L} / \mathrm{min}$.

This minimum demand of $7.78 \mathrm{~L} / \mathrm{min}$ is depicted in Fig. 11 by a horizontal hyphened line. Result shows that the $T_{\text {short }}$ initiates after 46th day from the start of the recession period and prolongs for a span of 167 days (i.e., = 213-46). Incorporating the above-mentioned data in Eq. (4), $O_{\mathrm{sc}-\mathrm{w}}$ is evaluated equal to:

$O_{\mathrm{sc}-\mathrm{w}}=11,16,648 \mathrm{~L}$.

Considering the wastage and increased water use $W=10 \%$, the optimized storage capacity $O_{\mathrm{sc}}$ is evaluated as:

$O_{\mathrm{sc}}=11,16,648 \times\left(1+\frac{10}{100}\right)=12,28,313 \mathrm{~L}$.

The optimized storage capacity $O_{\text {sc }}$ evaluated in calculation (9) is for the village as a whole. However, the individual storage is usually preferred over combined storage in terms of its management and judicial use of water. Moreover, the lack of ownership and maintenance of storage structure along with space requirement are the major constraints against the adoption of combined storage structure. Combined water storage structure system is successful only where the water distribution, supply, and the maintenance are governed by any government agency. Consider that an average size of a family in the village comprises four members. Therefore, the total number of families residing in the village is equal to 40 (i.e., 160/4). In that case, the total storage capacity required for one family is: 


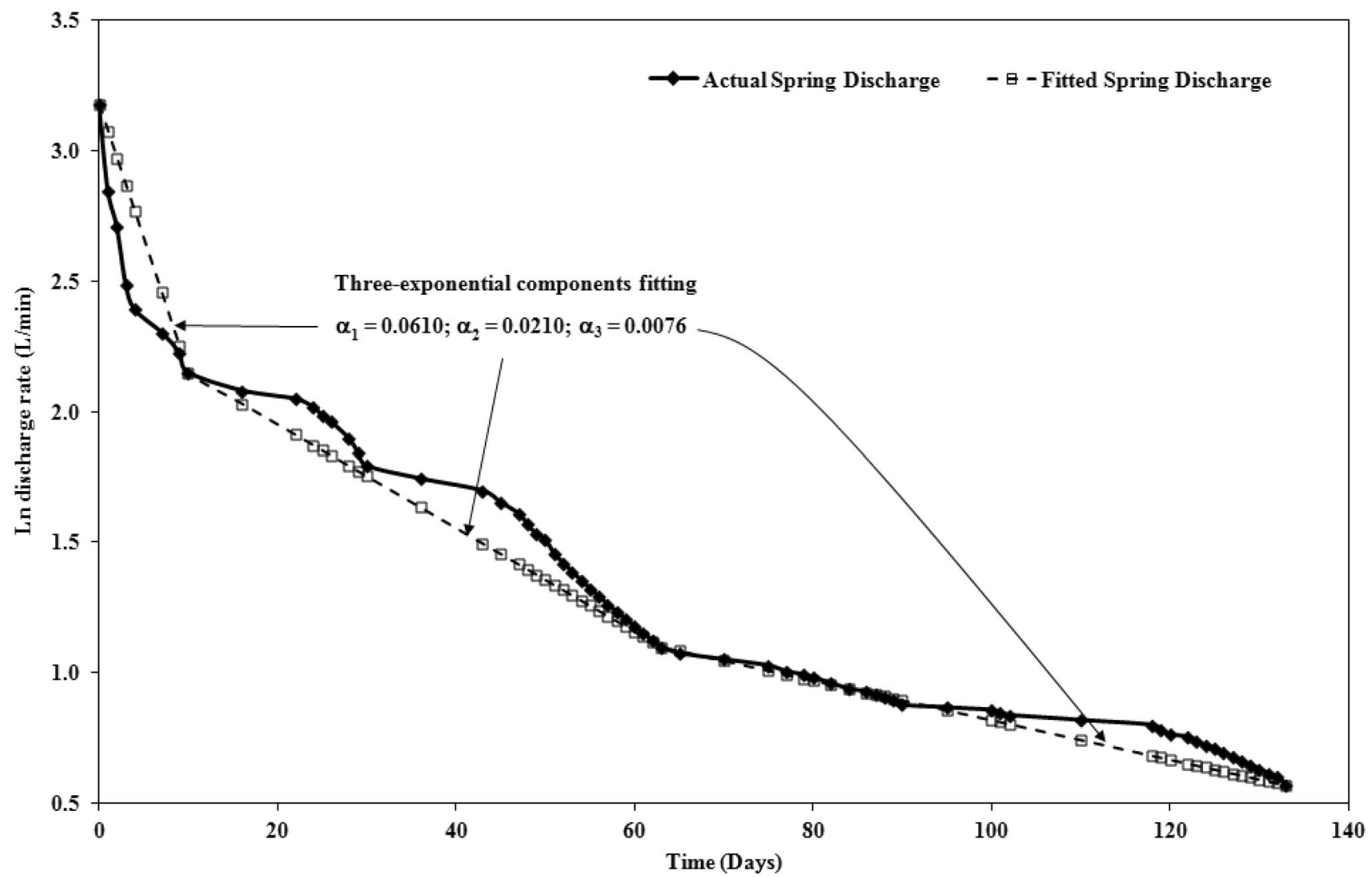

Fig. 9 Recession curve for the year 2006 fitted in three-exponential components

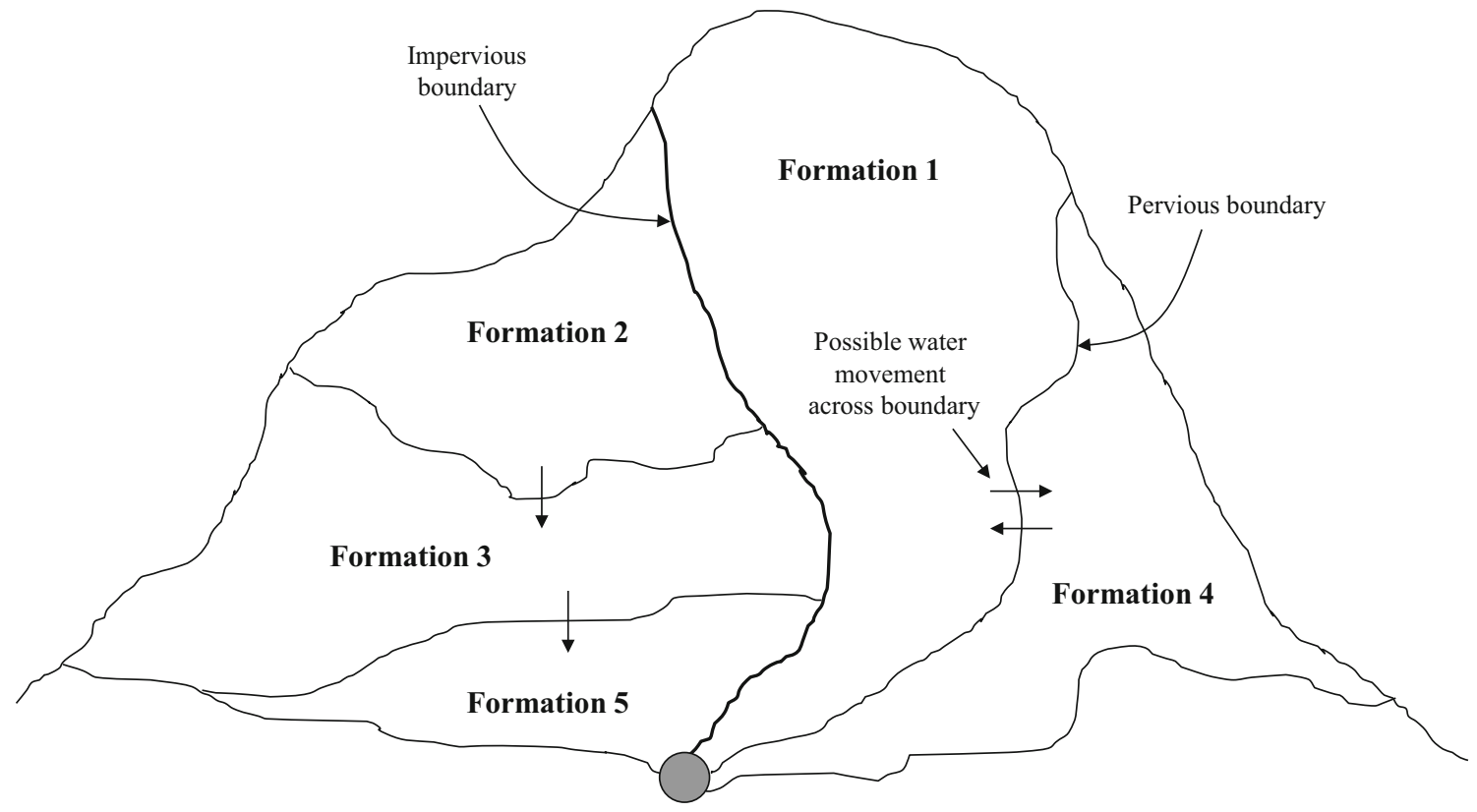

Spring orifice

Fig. 10 Hypothetically sketched spring catchment showing five formations having different permeability values 
Table 1 Comparison between actual and computed spring yields

\begin{tabular}{|c|c|c|c|c|c|c|c|}
\hline \multirow[t]{2}{*}{ Year } & \multirow{2}{*}{$\begin{array}{l}\text { Exponential } \\
\text { component(s) }\end{array}$} & \multirow{2}{*}{$\begin{array}{l}\text { Exponential } \\
\text { coefficients (i.e., } \\
\text { slopes) }\end{array}$} & \multirow{2}{*}{$\begin{array}{l}\text { Initial discharge } \\
\text { rate }(\mathrm{L} / \mathrm{min})\end{array}$} & \multirow{2}{*}{$\begin{array}{l}\text { Duration } \\
\text { (days) }\end{array}$} & \multicolumn{2}{|c|}{ Spring yield (million-liters) } & \multirow{2}{*}{$\begin{array}{l}\text { Over }(+) / \text { under }(-) \\
\text { prediction from actual }(\%)\end{array}$} \\
\hline & & & & & $\begin{array}{l}\text { Evaluated from } \\
\text { computed data }\end{array}$ & $\begin{array}{l}\text { Evaluated from } \\
\text { recorded data }\end{array}$ & \\
\hline \multirow[t]{6}{*}{1999} & One & $\alpha_{1}=0.0197$ & 47.61 & 129 & 3.206 & 1.780 & +80.13 \\
\hline & Two & $\alpha_{1}=0.1547$ & 47.61 & 5 & 2.080 & 1.780 & +16.80 \\
\hline & & $\alpha_{2}=0.0143$ & 21.97 & 124 & & & \\
\hline & Three & $\alpha_{1}=0.1547$ & 47.61 & 5 & 1.602 & 1.780 & -10.01 \\
\hline & & $\alpha_{2}=0.0291$ & 21.97 & 41 & & & \\
\hline & & $\alpha_{3}=0.0069$ & 6.66 & 83 & & & \\
\hline \multirow[t]{6}{*}{2003} & One & $\alpha_{1}=0.0228$ & 60.00 & 156 & 3.690 & 2.069 & +78.16 \\
\hline & Two & $\alpha_{1}=0.0500$ & 60.00 & 53 & 2.020 & 2.069 & -2.34 \\
\hline & & $\alpha_{2}=0.0088$ & 4.24 & 103 & & & \\
\hline & Three & $\alpha_{1}=0.0500$ & 60.00 & 53 & 2.100 & 2.069 & +1.51 \\
\hline & & $\alpha_{2}=0.0021$ & 4.24 & 52 & & & \\
\hline & & $\alpha_{3}=0.0156$ & 3.81 & 51 & & & \\
\hline \multirow[t]{6}{*}{2004} & One & $\alpha_{1}=0.0334$ & 60.60 & 93 & 2.500 & 1.633 & +52.85 \\
\hline & Two & $\alpha_{1}=0.0676$ & 60.60 & 24 & 1.660 & 1.633 & +1.38 \\
\hline & & $\alpha_{2}=0.0215$ & 11.97 & 69 & & & \\
\hline & Three & $\alpha_{1}=0.0676$ & 60.60 & 24 & 1.632 & 1.633 & -0.08 \\
\hline & & $\alpha_{2}=0.0239$ & 11.97 & 31 & & & \\
\hline & & $\alpha_{3}=0.0195$ & 5.71 & 38 & & & \\
\hline
\end{tabular}

Table 2 Parameters of the exponential components for the years 1999-2006

\begin{tabular}{|c|c|c|c|c|c|c|c|c|c|c|}
\hline (1) & Year & 1999 & 2000 & $2001^{\mathrm{a}}$ & 2002 & 2003 & 2004 & 2005 & 2006 & $\begin{array}{l}\text { Mean/W. } \\
\text { mean }\end{array}$ \\
\hline (2) & Rainfall (mm) & 939.70 & 1334.40 & 719.10 & 1254.60 & 1173.80 & 1174.70 & 1386.90 & 897.00 & 1110.03 \\
\hline (3) & $Q_{01}(\mathrm{~L} / \mathrm{min})$ & 47.61 & 60.00 & 3.30 & 60.60 & 60.00 & 60.60 & 125.00 & 24.00 & 62.54 \\
\hline (4) & $\alpha_{1}\left(\right.$ days $\left.^{-1}\right)$ & 0.1547 & 0.1258 & 0.0027 & 0.0745 & 0.0500 & 0.0676 & 0.0610 & 0.1029 & $0.0699(\mathrm{~W})$ \\
\hline (5) & $\begin{array}{l}\text { Duration for which the slope } \alpha_{1} \text { is } \\
\text { evaluated (days) }\end{array}$ & 5 & 11 & 54 & 23 & 53 & 24 & 40 & 10 & $\sim 24$ \\
\hline (6) & $Q_{02}(\mathrm{~L} / \mathrm{min})$ & 21.97 & 15.03 & 2.85 & 10.92 & 4.24 & 11.97 & 10.91 & 8.58 & 11.95 \\
\hline (7) & $\alpha_{2}\left(\right.$ days $\left.^{-1}\right)$ & 0.0291 & 0.0179 & 0.0036 & 0.0196 & 0.0021 & 0.0239 & 0.0210 & 0.0198 & $0.0186(\mathrm{~W})$ \\
\hline (8) & $\begin{array}{l}\text { Duration for which the slope } \alpha_{2} \text { is } \\
\text { evaluated (days) }\end{array}$ & 41 & 72 & 53 & 44 & 52 & 31 & 80 & 53 & $\sim 54$ \\
\hline (9) & $Q_{03}(\mathrm{~L} / \mathrm{min})$ & 6.66 & 4.15 & 2.35 & 4.61 & 3.81 & 5.71 & 2.03 & 3.00 & 4.28 \\
\hline (10) & $\alpha_{3}\left(\right.$ days $\left.^{-1}\right)$ & 0.0069 & 0.0036 & 0.0356 & 0.0119 & 0.0156 & 0.0195 & 0.0076 & 0.0076 & $0.0087(\mathrm{~W})$ \\
\hline (11) & $\begin{array}{l}\text { Duration for which the slope } \alpha_{3} \text { is } \\
\text { evaluated (days) }\end{array}$ & 83 & 119 & 16 & 55 & 51 & 38 & 93 & 70 & $\sim 73$ \\
\hline (12) & Duration of actual recession period (days) & 129 & 202 & 123 & 122 & 156 & 93 & 213 & 133 & $\sim 151$ \\
\hline
\end{tabular}

W weighted mean (on the basis of duration of particular component (row 5) that is used for evaluating slope)

a Though the spring's recession curve parameters for the year 2001 are tabulated, for the analysis purpose, the values are not included due to the spring's extreme behavior in this particular year

$O_{\text {sc }} / 40=12,28,313 / 40=\sim 30,708 \mathrm{~L}$.

From the above example, it is evident that a family of four members residing in a village (i.e., depending on a single spring and having a population of 160) can fulfill their domestic water needs during an extreme water shortage period of 167 days by constructing a water storage structure of capacity $\sim 30,708 \mathrm{~L}$. This evaluated storage is about $34 \%$ less from the actual water requirement of the family during $T_{\text {short }}$ (i.e. 167 day $\times 4 \times 70 \mathrm{Lpcd}=46,760 \mathrm{~L}$ ). 
Table 3 Comparison of the spring yield predicted using the developed discharge function with the actual

\begin{tabular}{lrrrrrrrrr}
\hline Year & \multicolumn{1}{c}{1999} & 2000 & 2001 & 2002 & 2003 & 2004 & 2005 & 2006 & Mean \\
\hline Predicted yield of the spring (million-liters) & 1.46 & 2.05 & NA & 1.85 & 1.93 & 1.70 & 4.31 & 0.74 & 1.997 \\
Actual yield of the spring (million-liters) & 1.78 & 2.04 & 0.47 & 1.72 & 2.07 & 1.63 & 3.94 & 0.90 & 2.013 \\
Percentage error in predicting yield over actual & -17.82 & +0.26 & - & +7.28 & -6.50 & +4.08 & +9.36 & -17.77 & -0.78 \\
\hline
\end{tabular}

$N A$ not considered in the analysis

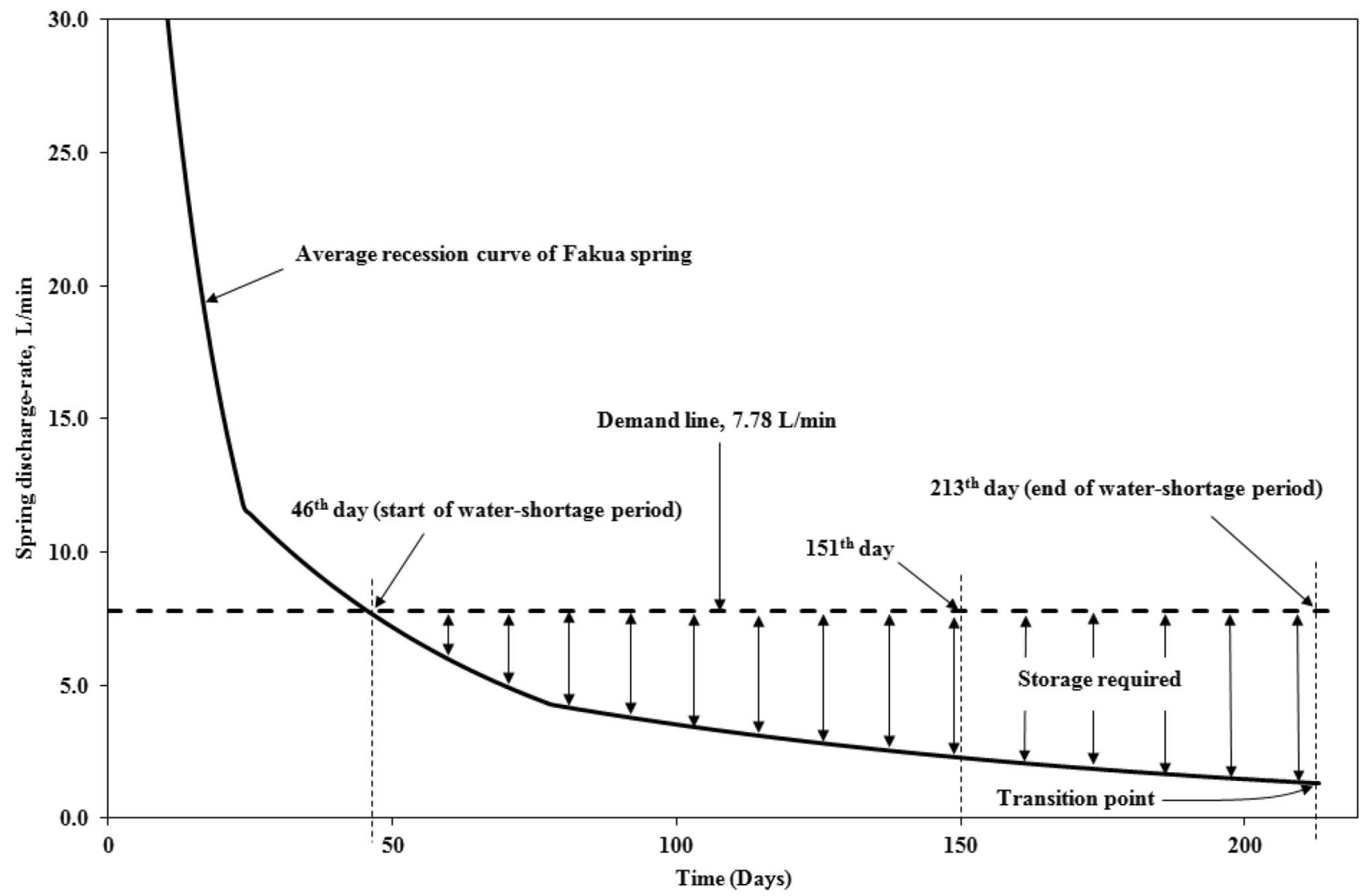

Fig. 11 Characteristic recession curve of Fakua spring. Difference in demand and availability is also shown by the shaded area during the water shortage period

Following the similar steps, $O_{\text {sc }}$ required for $T_{\text {short }}$ period ranging from 10 to 167 days is evaluated and is graphically shown in Fig. 12. Perusal of the figure indicates that the slope of the $O_{\text {sc }}$ curve is continuously increasing with the increase in the $T_{\text {short }}$, and due to this, the per cent reduction in the $O_{\mathrm{sc}}$ from the actual demand is declining. For example, the per cent reduction in $O_{\mathrm{sc}}$ for $T_{\text {short }}$ of 10 days is $89.11 \%$, whereas this reduction for the $T_{\text {short }}$ of 167 days is only $34.33 \%$. The basic reason for this variation is the continuously declining discharge rate of the spring. Therefore, the slope of the $O_{\text {sc }}$ curve completely depends on the discharge characteristics of the spring. In case the spring dries up, the per cent reduction in storage capacity will become zero and the curve for optimized capacity will overlie the actual demand curve.

In the literature, one can find other empirical, experimental, and analytical approaches for evaluating the storage capacities of river reservoirs (McMohan et al. 2007), and for that, continuous flow rate data (whether the reservoir is within-year system or an over-year system) of the source are required. Generally, the water managers prefer the Rippl's mass curve method or sequent peak algorithm (SPA) for the purpose (Aksoy 2001). However, in the present study, our analyses are limited to the recession period, and for that, the discharge rate data of the spring, for only this period, are required. For comparing the results, the capacity of the 


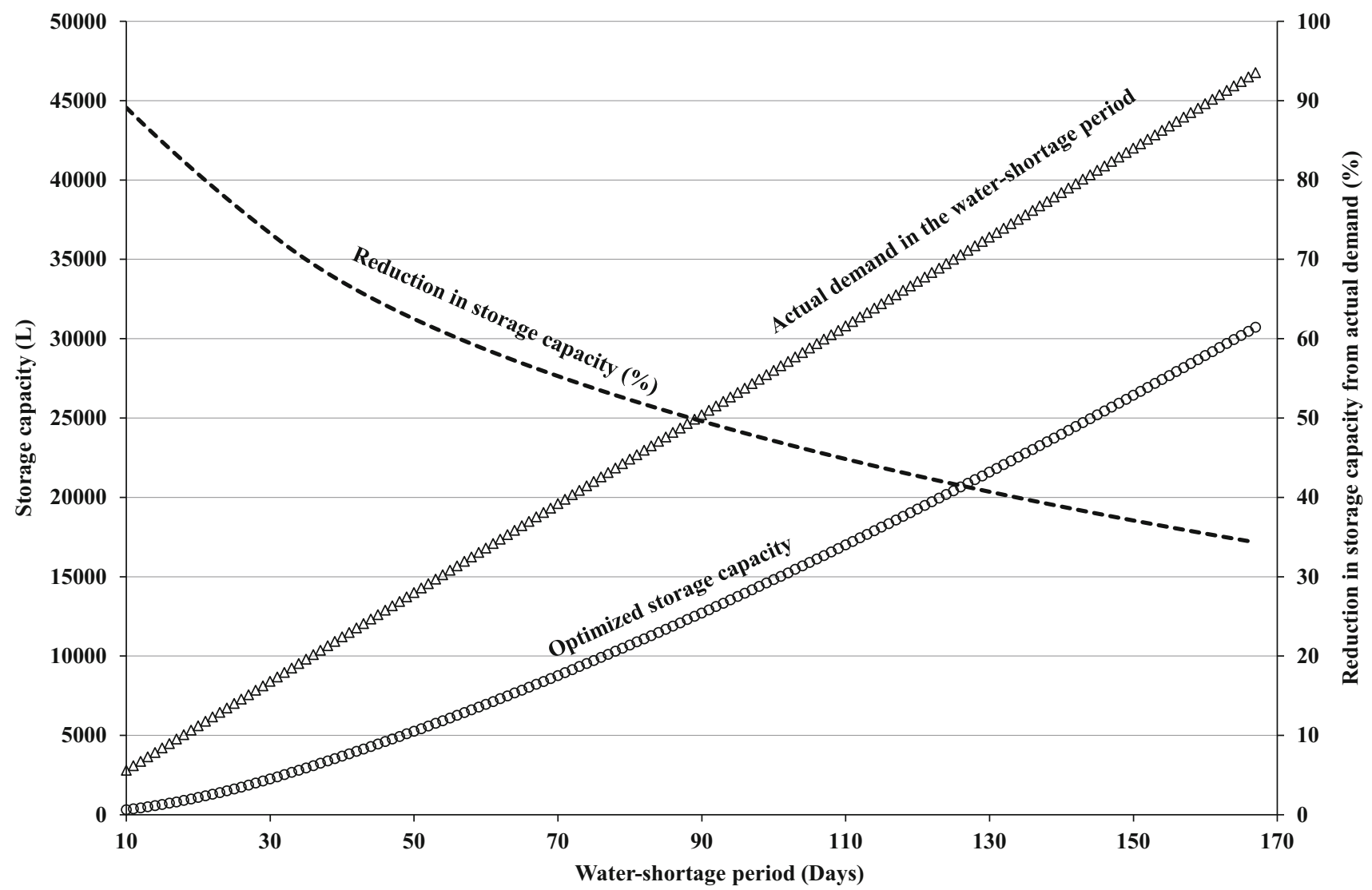

Fig. 12 Graph showing the difference of optimized storage capacity from the actual demand

storage structure is also evaluated by the SPA using the same 8-year discharge data of Fakua spring. From the different peaks and subsequent troughs, maximum storage capacity has been obtained equal to $37,81,000 \mathrm{~L}$ for total 160 persons, which, for one family (comprising 4-members), averages equal to 94,525 L. Noticeably, the storage capacity evaluated using SPA is extremely larger than the actual demand evaluated for $T_{\text {short }}$ (i.e., 46,760 L) as well as the optimized (i.e., 30,708 L) using proposed analytical function (5). From the analyses, it is obvious that the extremely low discharge rate of the spring during the recession period of year 2001-2002 got more weightage in SPA which reflected in the form of larger capacity of storage structure. Apparently, the vice versa of last statement is equally true. However, optimizing the capacity of the storage structure on such uncertain extreme behaviors of the spring is not correct practically. Most importantly, with the use of the developed analytical function, we can timely predict the discharge rate of the spring (basically from the start of the recession period). If the results show that the spring will discharge with extreme low rate in the recession period, other measures (like restricted use of water and/ or collection of water from the other seasonal springs/ streams to fill the storage structure) can be adapted well within time to cope with the upcoming water shortage period. The results and the above discussion justify that the spring discharge for the recession period can be managed much more effectively and economically in comparison to flow mass curve methods. Therefore, the developed analytical function in the present study is an efficient spring water management tool and not just a storage structure's capacity calculator.

\section{Summary and conclusions}

The major population in the Himalayan region is dependent on the springs and the natural streams for their daily water needs. However, the continuously changing climate has drastically diminished the flowing rate of the life-supporting springs in the region. The only feasible adaption technique to cope with this water scarcity in recession period is to store when it is in excess during monsoon/post-monsoon season in an accurately optimized storage structure. And for this, an analytical function has been proposed in the present study. The analytical function's applicability has been shown by analyzing the 8-year (i.e. 1999-2006) temporal 
discharge data of a western-Himalayan gravity spring. The following conclusions have been drawn from the analyses:

1. The analyses show that the number of exponential components required to accurately fit the recession curve actually represents the distinct porous mediums within the spring catchment and all these are demarcated with varied discharging characteristics due to different formation properties. In spite of the fact that these distinct porous mediums of the catchment contribute collectively to the spring discharge, their existence is reflected by the change in general slope of the recession curve. Therefore, it is concluded that the general hypothesis followed till date that recession curves can be fitted accurately with only two mathematical components is not correct. It solely depends on the number of porous mediums having distinct formations within the spring catchment. However, from the analyses of hydrograph (especially recession curve), it is difficult to delineate the actual geometry, location, and dimensions of these mediums (at least at the present stage). Study of the recession curves for the 8-year data of Fakua spring concludes that its catchment comprises three storage mediums majorly and that are reflected by representing the recession curves with three exponential components.

2. For formulating the discharge function of a spring, its characteristic parameters are required, and the year-onyear variation in these parameters (especially exponential coefficients) is the major constraint. This variation in exponential coefficients can be quantified by evaluating the ratios of its maximum to minimum values for all the data monitoring years. Ideally, this ratio will approach to unity for a spring having similar discharging pattern for all its recession periods. Practically, it is not feasible in case of any natural hydrological system, and certainly, this is the major constraint. Data analyses show that errors in the computed results for most of the recession periods remain within $10 \%$ when the said ratio for firstexponential coefficients remains less than five. In the present study, the exponential coefficients for the fitted first-exponential components for the 8-years range from 0.0027 to 0.1547 (with ratio 57.29). Extremely low rainfall in year $2001(\sim 35 \%$ less than the annual average of $1110.03 \mathrm{~mm}$ ) may be the most likely reason for this extreme variation and that is why the weighted mean of all exponential coefficients is evaluated by excluding the data of year 2001. The results of the formulated spring discharge function are comparable with the recorded data.

3. The applicability of the formulated analytical function is shown by an example considering realistic data. Based on the behavior of Fakua spring, it is evaluated that a family of four members residing in a village having population of 160 can fulfill its domestic water needs during an extreme water shortage period of 167 days by constructing a water storage structure of capacity $\sim 30,708$ L. From the results, it is concluded that with the increase in the water shortage period, per cent reduction in the optimized storage from the actual demand decreases and this variation is due to the continuously declining discharge rate of the spring. Therefore, it is also established that the slope of the optimized storage capacity curve completely depends on the discharge characteristics of the spring. The overlying of optimized capacity curve on the actual demand curve indicates that the per cent reduction in storage capacity becomes zero and spring has dried up. In nut shell, the analytical function developed in the present study can be conveniently used for optimizing the storage capacity for nullifying the impact of water scarcity during recession period.

4. It has also been concluded that the available discharge from the spring during recession period can be managed much more efficiently and economically in comparison to flow mass curve methods as, with the use of formulated analytical function, we can timely predict the discharge rate of the spring for the upcoming recession period.

Acknowledgments The data used in this paper is procured from the project named All India Coordinated Research Project on Groundwater Utilization (AICRP-GWU), Department of Irrigation and Drainage Engineering, G. B. Pant University of Agriculture and Technology, Pantnagar, Uttarakhand, India. The Project is supported by Indian Council of Agricultural Research, New Delhi.

\section{Compliance with ethical standards}

The author declares that he has no conflict of interest. No animal is involved while collecting field data.

\section{References}

Aksoy H (2001) Storage capacity for river reservoirs by waveletbased generation of sequent-peak algorithm. Water Resour Manage 15:423-437

Amit H, Lyakhovsky V, Katz A, Starinsky A, Burg A (2002) Interpretation of spring recession curves. Groundwater 40(5):543-551

Bam B (2011) Interpreting recession curves of a contact spring at Ranichauri, Uttarakhand. B Tech project report, Department of Soil and Water Engg, College of Agric Engg and Post-Harvest Tech, Central Agric Univ, Ranipool, Gangtok, Sikkim

Beniston M (2003) Climatic change in mountain regions: a review of possible impacts. Clim Change 59:5-31

Boussinesq J (1904) Recherches theoretique sur l'ecoulement des nappes d'eau infiltrees dans le sol et sur le debit des sources. J de Math Pures et Applignées 10(1):5-78 
Chang Y, Wu J, Liu L (2015) Effects of the conduit network on the spring hydrograph of the karst aquifer. J Hydrol 527:517-530

Diodata N, Guerriero L, Fiorillo F, Esposito L, Revellino P, Grelle G, Guadagno FM (2014) Predicting monthly spring discharges using a simple statistical model. Water Resour Manage 28:969-978

Gansser A (1964) Geology of the Himalayas. Interscience, London

Hofer T, Messerli B (2006) Floods in Bangladesh: history, dynamics and rethinking the role of the Himalaya. UN University Press, New York

IPCC (2007) Climate change 2007: climate change impacts, adaptation and vulnerability, Working Group II contribution to the Intergovernmental Panel on Climate Change, Fourth Assess Report, Summary for policymakers

Khastagir A, Jayasuriya N (2010) Optimal sizing of rain water tanks for domestic water conservation. J Hydrol 381:181-188

Levison J, Larocque M, Ouellet MA (2014) Modeling low-flow bedrock springs providing ecological habitats with climate change scenarios. J Hydrol 515:16-28

Ma X, Xu JC, Luo Y, Aggarwal SP, Li JT (2009) Response of hydrological processes to land cover and climate change in Kejie Watershed, Southwest China. Hydrol Process 23(8):1179-1191

Mall RK, Gupta A, Singh R, Singh RS, Rathore RS (2006) Water resources and climate change: an Indian perspective. Curr Sci 90(12): 1610-1626

Mangin A (1975) Contribution a l'étude hydrodinamique des aquif'eres karstiques. Ann de Spéléol 29:285-382, 495-601, 30:21-124

McMohan TA, Pegram GGS, Vogel RM, Peel MC (2007) Revisiting reservoir storage-yield relationships using a global streamflow database. Adv Water Resour 30:1858-1872
MoDW\&S (2011) Report of the working group on rural domestic water and sanitation, 12th 5 year plan-2012-17. Ministry of Drinking Water and Sanitation, Gov of India

Mukherjee S, Joshi R, Prasad RC, Vishvakarma SCR, Kumar K (2014) Summer monsoon rainfall trends in the Indian Himalayan region. Theor Appl Climatol. doi:10.1007/s00704-014-1319-4

Qiu J (2008) The third pole. Nature 454:393-396

Rees GH, Collins DN (2006) Regional differences in response of flow in glacier-fed Himalayan rivers to climate warming. Hydrol Process 20:2157-2167

Shrestha AB, Wake CP, Dibb JE, Mayyewski PA (2000) Precipitation fluctuations in the Nepal Himalaya and its vicinity and relationship with some large-scale climatology parameters. Int J Climatol 20:317-327

Singh P, Kumar V, Thomas T, Arora M (2008) Changes in rainfall and relative humidity in river basins in northwest and central India. Hydrol Process 22:2982-2992

Tambe S, Arrawatia ML, Bhutia NT, Swaroop B (2011) Rapid, cost effective and high resolution assessment of climate-related vulnerability of rural communities of Sikkim Himalaya, India. Curr Sci 101(2):165-173

Tiwari PC, Joshi B (2012) Environmental changes and sustainable development of water resources in the Himalayan headwaters of India. Water Resour Manage 26:883-907

Vashisht AK, Sharma HC (2007) Study on hydrological behavior of a natural spring. Curr Sci 93(6):837-840

Xu JC (2008) The highlands: a shared water tower in a changing climate and changing Asia. Working paper no. 64, World Agrofor Cent, Nairobi, Kenya

Xu JC, Grumbine RE, Shrestha A, Eriksson M, Yang X, Wang Y, Wilkes A (2009) The melting Himalayas: cascading effects of climate change on water, biodiversity, and livelihoods. Conserv Biol 23(3):520-530 